\title{
Estimation of Local Recreational Value of Seethawaka Wet Zone Botanical Garden
}

\author{
Maduwanthika M.C.A.*, Gunawardene U.A.D.P. \\ Department of Forestry and Environmental science, University of Sri Jayewardenepura, \\ Sri Lanka \\ *chathurikaamali9249@gmail.com
}

\begin{abstract}
The Seethawaka wet zone Botanic garden is a new botanical garden in the wet zone of Sri Lanka. The garden is entrusted with the dual mandate of providing quality recreation opportunity to visitors while conserving the highly threatened wet lowland forest flora of Sri Lanka. The study intends to estimate local recreational value of the garden which could provide guidance on further investments and improvements of the garden. The economic approach used to estimate the recreational value was the zonal travel cost method. The method involves dividing the surrounding area into concentric zones of increasing distance, which represented increasing levels of travel cost. A questionnaire survey was conducted at the garden to determine zone of origin, visitation rates, travel cost and various socio economic characteristics. Information was gathered from 200 local visitors to garden through direct interviews using a structured questionnaire. The data generated were used to regress visitation rates against the total travel cost and urban population fraction of each zone. The estimated local recreational value of the garden per annum was LKR 283 million and the consumer surplus at the current entrance fee of LKR 60 is LKR 275 million per annum. This figure can be used to demonstrate the contribution of a botanic garden to the economy and to attract more funds to develop infrastructural facilities inside the garden from the government allocations.
\end{abstract}

Key words: Travel cost method, Seethawaka wet zone, Recreational value 